Japanese Psychological Research

1900 , Vol. 32 . No. 4, $105-171$

\title{
The development of distributive justice and reward allocation in children ${ }^{1}$
}

\author{
YAYOI WATANABE ${ }^{2}$ \\ Department of Psychology, Faculy of Education, Shiznoha Unitersily, Ooya, Shizuoka 422
}

\begin{abstract}
The purpose of the present study was to investigate the interaction between the distributive justice development and social context which could infuence reward allocation. Subjects $(\mathcal{N}=$ 150) ranged from kindergartner to third graders. Each subject was administered a positivejustice interview to assess the level of his/her reasoning about distributive justice. Then the subject was told that he/she would help to make badges as many as he/she could, and worked on a task with a fictitious partner whose performance was superior, equal, or inferior to his/her own. The subject was then given rewards to divide between the partner. Results indicated that the distributive justice levels did not directly determine developmental trends in the reward allocation and also that the interaction of distributive justice levels with performance was one of the substantial determinants of the reward allocation.
\end{abstract}

Key words: reward allocation, distributive justice, development, social context, performance.

In developmental psychology, the first major theory of the development of distributive justice was proposed by Piaget (1965). He found that young children accepted equal treatment as fair. But he did not attempt to investigate directly the antecedents of developmental changes in fairness judgement. During the 1970's, there was a revival of interest in children's judgements about distributive justice. The new interest in distributive justice had two sources.

First, Kohlberg's (1969) theory of stages in moral reasoning provoked a general concern with qualitative changes in thinking about justice. Damon (1975, 1977, 1980) studied distributive justice most extensively. Damon's model of the development of reasoning about distributive justice is similar to Kohlberg's general model of moral development. $\mathrm{He}$ assumed that children pass through stages in an invariant sequence and that the

A brief version of this paper was presented at the XXIV International Congress of Psychology, Sydney, Australia, 1988.

2 I would like to thank Professors Seijyun Takano, and Kazuaki Sugihara for their critical reading and editing an ealier version of this paper. maturity of children's reasoning about moral dilemmas is closely related to their cognitive development. He found that six levels of distributive justice reasoning were strongly related to age in a cross sectional study. Table 1 taken from Damon presents brief descriptions of conception of positive-justice.

In Japan, Watanabe (1986a) investigated the cross-cultural generality of distributive justice construction. Damon's method of distributive justice interview was translated into Japanese with minimal modification. The reward was changed from money to ice cream, because it was felt to be a more suitable reward for young children in Japan. And also the description of one character, 'the poor boy' was removed, because most Japanese think they belong to the middle class. It was administered to 227 children from four through nine years old. The results indicated that the stage progression had been validated in Japan as well as in the U.S.A.

But there were some differences, that is, there were fewer children at the 1-B level and many more children at the 1-A level in Japan as opposed to the U.S.A. The Japanese often used the expression 
Level 0-A

Positive-justice choices derive from wish that an act occur. Reasons simply assert the wishes rather than attempting to justify them ("I should get it because I want to have it").

Level $0-B$;

Choices still reflect desires but are now justified on the basis of external, observable realities such as size, sex, or other physical characteristics of persons (e.g., we should get the most because we are girls). Such justifications, however, are invoked in a fluctuating, after-the-fact manner and are self-serving in the end.

Level 1-A :

Positive-justice choices derive from notions of strict equality in actions (i.e., that everyone should get the same). Equality is seen as preventing complaining, fighting, "fussing," or other types of conflict.

Level 1-B:

Positive-justice choices derive from a notion of reciprocity in actions: that persons should be paid back in kind for doing good or bad things. Notions of merit and deserving cmerge.

Level 2-A:

A moral relativity develops out of the understanding that different persons can have different, yet equally valid, justifications for their claims to justice. The claims of persons with special needs (e.g., the poor) are weighted heavily. Choices attempt quantitative compromises between competing claims.

Level 2-B:

Considerations of equality and reciprocity are coordinated such that choices take into account the claims of various persons and the demands of the specific situation. Choices are firm and clear-cut, yet justifications reflect the recognition that all persons should be given their due (though, in many situations, this does not mean equal treatment).

"allocating the same rewards to each person is best, because we don't want to get into fights" or "Dividing the rewards equally is good." In comparison, more Americans used the expression, "I get much more, because I worked harder" or "I have the right to get more rewards, because I was more competent."

Also, the Japanese used more affectionate expressions, compared to the Americans. These differences result from the Japanese tendency to put emphasis on maintaining good interpersonal relationships, whereas the Americans tend to put emphasis on performance and individuality. Japanese also often have a strong sense of traditional duty and humanity.

Second, social psychologists investigated principles of justice. Occasionally the principles first investigated in research with adults were later studied with chil- dren. They have brought out the influence of the social context on fairness judgements and behavior. Most studies in this area have focused on the distinction between the equality and equity principles (Leventhal \& Anderson, 1970), not on the cognitive development investigated by Piaget, Kohlberg etc. They were interested in how an individual who distributes rewards to other persons follows one of two norms of justice. Some social psychologists (Lane \& Messe, 1971 etc.) suggested the equity model (Adams, 1963). Some (Lane \& Coon, 1972 etc.) suggested an equality norm. Similar studies with young children have produced contradictory results.

Watanabe (1986b) indicated that the children's allocation behavior does change with age in the children who were told their performance was inferior to that of 
Table 2

Frequency distribution of positive-justice levels across ages and sexes

\begin{tabular}{crrrrrrrr}
\hline & \multicolumn{3}{c}{ Age } & \multicolumn{2}{c}{ Sex } \\
\hline Level & 4 & 5 & 6 & 7 & 8 & 9 & M & F \\
\hline $0-A$ & 8 & 4 & 3 & 0 & 0 & 0 & 6 & 9 \\
$0-B$ & 11 & 4 & 0 & 0 & 0 & 0 & 9 & 6 \\
I-A & 1 & 0 & 22 & 6 & 1 & 0 & 14 & 16 \\
1-B & 0 & 7 & 7 & 7 & 8 & 0 & 16 & 13 \\
$2-A$ & 0 & 0 & 0 & 11 & 16 & 3 & 14 & 16
\end{tabular}

their partners. Younger children tended to distribute rewards with more self-interest, regardless of their own performance. And children between the ages of four and seven prefered to divide rewards equally rather than follow an equity norm, whereas this preference was reversed in eight-year-old children.

The models for the development of these two traditions are very different. Developmental psychologists have not weighed the actual reward allocation behavior investigated by manipulating " social condition." They have focused solely on the relation between subjects' age and their conceptions of distributive justice. On the other hand, social psychologists have not investigated this outside the laboratory, ignoring the moral development of justice. Children's distributive justice should be considered from these two points of view.

The purpose of the present author's study was to clarify the cognitive process before deciding which principle of reward allocation should be selected. Damon (1981) tried to answer the question of how cognition about justice relates to children's social conduct during real-life, peer-group situations on problems of fairness. The results showed that children's hypothetical reasoning about justice is indeed related to their social behavior in actual justice situations. But Damon examined only whether children would distribute rewards equally or unequally, and did not refer to some other principles (for example, "equity").
Also their distribution was investigated, broken down, not by distributive justice level, but by age group. Another purpose of the present study was to investigate the relation between distributive justice and "social condition" which would have an influence on reward allocation behavior.

Specifically, it was predicted that; (a) children with lower levels (0-A or $0-B)$ would act more self-interestedly when allocating rewards in any "social condition" than others; (b) children at 1-A whose justice derived from notions of strict equality principle would employ the equality principle in any "social condition"; (c) children at 1-B whose justice derived from notions of reciprocity would employ the equity principle in any "social condition"; (d) children at 2-A would act differently according to " social condition."

\section{Method}

\section{Subjects}

The subjects were 150 children drawn from kindergarten, elder kindergarten, and from the first, second, and third grades of an elementary school.

Twenty-five subjects were dismissed because two raters did not agree on judging levels, and six subjects were also dismissed because they indicated that during the experiment they had realized the experimenter were giving them false information about their fictitous partner (Table 2). 


\section{Procedure}

First, half of the subjects were given a standard version of the positive-justice interview (Watanabe, 1986a). This interview posed to subjects a hypothetical problem in distributive justice which was encountered by a group of school children and asked them to reason out issues of fairness embedded in this problem.

This interview contained two stories. Each story was administered to children with a picture to help them understand it. The sex of the subject determined the sex of the characters in the stories. Girls encountered girls. Boys encountered boys.

In the case of boys, the first story was this:

All of these boys were in the same class together. One sunny day their teacher took them for a picnic in a nearby garden. After having lunch, they spent the whole afternoon drawing pictures.

Akio drew the most, he drew three pictures.

Kazuo played and neglected to paint, so he drew two pictures.

Satoshi drew only one picture because he had a headache.

Takeshi drew two pictures, and his pictures were the most beautiful.

And then a man taking a walk saw them, and said, "I want these pictures. They gave him their pictures. He was very pleased and gave them eight ice cream cones in exchange. The second one was also used.

After reading each story, the subject was given card board cut-out representing the rewards and was asked as follows (after the first story): "What do you think they should do with these? How would you distribute these ice cream cones?", "Akio drew the most pictures. Should he get the most ice cream?", "Kazuo was lazy, he didn't draw very much in comparison to the others. What about him?", and
"What is the best way to share equally?" and so on.

These stories and questions were administered with considerable flexibility, varying to fit the pattern of the individual subjects' responses. The stage score was determined for each subject from his/her responses according to a scoring guide.

Next, each child was taken to another room one at a time by a female experimenter and was asked to help make as many badges as he/she could. The experimenter indicated that another child was helping to make badges for the same length of time in another room. Children worked on this task with their fictitious partner.

Three kinds of experimental conditions were set. Subjects were tested at random, with 50 subjects for each experimental condition. For example, in the 'superior' condition, the subject was stopped after making seven badges. Then the experimenter stated she had to find out the number of badges the other child had made, and left the room.

After returning, she told the subject that the other child had made three badges. She laid the two work sheets side by side, and called the subject's attention to them. Other conditions were 'equal,' in which the subject and the hypothetical partner both made five badges, and 'inferior,' in which the subject made three badges and the partner made seven badges. The subjects were then given 10 rewards and were told to divide them between themselves and their partners. The experimenter strongly emphasized that the child could divide them in whatever way he wished. This procedure was followed as in Watanabe (1986b). The other half of the subjects were first given the experiments and were then interviewed.

\section{Results}

Table 3 presents the mean of rewards 
Table 3

Mean of rewards taken by subjects in each condition

\begin{tabular}{cccc}
\hline & & Condition & \\
\hline L.evel & $\begin{array}{c}\text { Inferior } \\
(\mathcal{N}=40)\end{array}$ & $\begin{array}{c}\text { Equal } \\
(\mathcal{N}=40)\end{array}$ & $\begin{array}{c}\text { Superior } \\
(\mathcal{N}=39)\end{array}$ \\
\hline $0-\mathrm{A}+0-\mathrm{B}$ & $5.40(1.90)$ & $5.00(0.00)$ & $5.40(0.70)$ \\
$1 \cdot \mathrm{A}$ & $5.10(0.32)$ & $5.10(0.32)$ & $5.10(1.66)$ \\
$1-\mathrm{B}$ & $4.30(1.06)$ & $5.30(0.95)$ & $6.00(1.73)$ \\
$2-A$ & $4.20(1.03)$ & $5.10(0.50)$ & $5.62(1.35)$
\end{tabular}

Note: Numbers in parentheses indicate the $S D_{3}$.

Table +

Frequency of subjects sharing rewards with their fictitious partner in differing allocation strategies

Inferior condition

\begin{tabular}{|c|c|c|c|c|c|}
\hline Level & Equality & Equity & Compromise & Selfish & Altruistic \\
\hline $0-A+0-B$ & $6(60.0)$ & $1(10.0)$ & $1(10.0)$ & $2(20.0)$ & $0(0.0)$ \\
\hline $1-A$ & $9(90.0)$ & $0(0.0)$ & $0(0.0)$ & $1(10.0)$ & $0(0.0)$ \\
\hline $1-B$ & $+(40.0)$ & $3(30.0)$ & $2(20.0)$ & $1(10.0)$ & $0(0.0)$ \\
\hline $2-1$ & $6(60.0)$ & $4(40.0)$ & $0(0.0)$ & $0(0.0)$ & $0(0.0)$ \\
\hline \multicolumn{6}{|l|}{ Equal condition } \\
\hline $0 . A+0 . B$ & & $10(100.0)$ & & $0(0.0)$ & $0(0.0)$ \\
\hline $1-A$ & & $9(90.0)$ & & $1(10.0)$ & $0(0.0)$ \\
\hline $1-B$ & & $9(90.0)$ & & $1(10.0)$ & $0(0.0)$ \\
\hline $2-\mathrm{A}$ & & $10(100.0)$ & & $0(0.0)$ & $0(0.0)$ \\
\hline \multicolumn{6}{|c|}{ Superior condition } \\
\hline $0 . A+0 . B$ & $7(70.0)$ & $1(10.0)$ & $2(20.0)$ & $0(0.0)$ & $0(0.0)$ \\
\hline $\mathrm{I}-\mathrm{A}$ & $6(60.0)$ & $2(20.0)$ & $1(10.0)$ & $0(0.0)$ & $1(10.0)$ \\
\hline $1-B$ & $6(66.7)$ & $2(22.2)$ & $0(0.0)$ & $1(11.1)$ & $0(0.0)$ \\
\hline $2-\mathrm{A}$ & $6(60.0)$ & $4(40.0)$ & $0(0.0)$ & $0(0.0)$ & $0(0.0)$ \\
\hline
\end{tabular}

Note: Numbers in parentheses indicate the percentages.

"Compromise" presents percentage of subjects who received the numbers of rewards between equality and equity.

Numbers are shown as above in "Lqual condition," because we could not distinguish among equality, equity, and compromise when input was equal.

subjects allocated to themselves in each positive-justice level and "social condition" (superior, equal, inferior). To examine the effects of the two variables on reward allocation, these data were analyzed via a two-way analysis of variance.

Results indicated that the main effect of the "social condition" and the interaction of positive-justice levels with "social condition" were significant, $F(2,107)$
$=6.52, p<.01$, and $F(6,107)=2.32, p<.05$. At each level the relation between the reward allocation norms and "social condition" was tested via an analysis of variance. As can be seen from Table 3, the tests indicated that there were significant effects at $1-\mathrm{B}$ and 2 -A levels $(F(2,26)$ $=4.29, \quad p<.05 ; \quad F(2,27)=5.07, \quad p<.01)$. This result suggested that children at 1-B and 2-A gave themselves more rewards 
according to "social condition."

Table 4 shows the relation between positive-justice levels and the norm of reward allocation. Twenty percent of lower level subjects (at 0-A, 0-B level) distributed rewards selfishly in inferior condition. But it was suprising that most of them employed the equality norm. As predicted, subjects at 1-A tended to employ the equality norm when distributing rewards, compared to other levels' subjects. Subjects at 1-B, 2-A tended to employ the equity norm, compared to others, but seemed to be quite confused in deciding which norm they should employ.

Thus, it was evident on the whole that positive-justice levels did not determine developmental trends in reward allocation directly. The percentage of the norm of equality was higher at every positive-justice level than had been expected. However, as had been predicted, the proportion of reward allocation by the norm of equity was seen to increase gradually according to level, although it was less than the norm of equality.

\section{Discussion}

This study investigated the relations of distributive justice levels to the reward allocation. The results of the present study are consistent with the conclusion that the child's cognition process should not be inferred solely from reward allocation behavior. Furthermore, the distributive justice levels did not directly determine the norm of reward allocation. "Social condition" (difference of the amounts of work) had a stronger effect on deciding the behavior of sharing. There were also specific predictable interaction effects between distributive justice levels and "social condition."

Children at 0-A, 0-B distributed more to themselves than did children at other reasoning levels in "inferior' condition, as had been predicted. But $60 \%$ of them allocated rewards equally. Their sharing behavior was very mechanical and without thinking. Their habitual ways of sharing at home should be defined to comprehend their sharing behavior.

It was predicted that subjects at 1-A employed the equality principle in all the conditions. But $40 \%$ of the subjects at 1-A in the superior condition did not allocate rewards equally. Although more subjects at 1-B preferred the equity allocation than those at $0-A, 0-B$, and $1-A$, there were few as a whole, contrary to the prediction. Subjects at the 2-A level were able to reason that both the equity and equality principles have their merits. As a result, they preferred the equity norm. However, this may be largely an abstract concept judging from the results of this study. Therefore the subjects would be quite confused as to which principles they should select in the three conditions. Individual personality traits may also influence the selection, not just distributive justice levels.

It is possible to conclude that these differences between the prediction and these results of the present study at each level arose from the effects of self-interest in reward allocation. Most subjects seemed to favor themselves in a real situation rather than in the hypothetical one because of getting the "real' rewards. Especially, it could be concluded that subjects at $0-\mathrm{A}, 0-\mathrm{B}$, and $1-\mathrm{B}$ had the right to get more rewards as if they were following the norm of equality in inferior condition. Also, subjects at 1-A tried to maximize their rewards as if they employed the norm of equity in superior condition. Otherwise, 1-B level subjects should employ the equity norm and 1-A level subjects should employ the equality norm regardless "social condition."

Therefore, both distributive justice development and situational factors should be considered on self-interest in order to comprehend the cognitive process of children. Especially, in the cxperimental 
situation, subjects were both the allocators and recipients of allocated rewards. But in the hypothetical situation, they played only the role of allocator. Selfish motives may influence different modes of reasoning in diflerent conditions, as in Damon's studies (1981).

Future research should focus on the question of what causes change in both distributive justice levels and the sharing behavior. We can predict that "conflict" in deciding which norm children should ober, or "conflict" between behaving self-interestedly and obeying the norm, would play the most important role in both distributive justice levels and the mode of distribution employed. Piaget (1932) has shown that peer interactions which posed cognitive conflicts for children would be most effective in facilitating change. It would be noteworthy to use peer debate situations in order to clarify children's cognitive process when distributing rewards. It would also be necessary to ask subjects the reason why they preferred the norm.

Moreover, other factors may distort the relations between distributive justice and reward allocation. The influence of personal factors (causal attribution, empathy) or other situational factors should be investigated to clarify the development of the sharing behavior.

\section{References}

Adams, J. S. 1963 Toward an understanding of inequity. Journal of Abnormal and Social Psychol- $\log y, 67,422-436$.

Damon, W, 1975 Early conceptions of positive justice as related to the development of operational reasoning. Child Development, 46, 301312.

Damon, W. 1977 The social world of the child. San Francisco: Jossey-Bass.

Damon, W. 1980 Patterns of change in children's social reasoning: A two-year longitudinal study. Child Development, 51, 1010-1017.

Damon, W. 1981 The development of justice and self-interest during childhood. In M.J. Lerner \& S. C. Lerner (Eds.), The justice motive in social behavior. New York: Plenum Press.

Kohlberg, L. 1969 Stage and sequence: The cognitive developmental approach to socialization. In D. A. Goslin (Ed.), Handbook of socialization theory and rescarch. Chicago: Rand McNally.

Lane, I. M., \& Coon, R. 1972 Reward allocation in preschool children. Child Development, 43, 1382-1389.

Lane, I. M., \& Mcsse, L. A. 1971 Equity and the distribution of rewards. Journal of Personality and Social Psychology, 20, 1-17.

Leventhal, G. S., \& Anderson, D. 1970 Self interest and the maintenance of equity. Journal of Personality and Social Psychology, 15, 57-62.

Piaget, J. 1965 The moral judgement of the child. (Trs. by M. Gabain) New York: Free Press., (Le Jugement moral chez l'enfant. 1932 Libraive: Félix Alcan.)

Watanabe, Y. 1986a Distributive justice development. Japanese Journal of Educational Psychol$\operatorname{og} y, 34,84-90$.

Watanabe, Y. 1986b The decision of reward allocation in children. Japanese Journal of Educational Psyclology, 34, 185-190.

(Received Dec. 26, 1988; accepted March 17, 1990) 